\title{
The Mechanism of Action of Flavoprotein - Catalyzed Reactions
}

\author{
V.Massey ${ }^{1}$ and S. Ghisla ${ }^{2}$
}

\section{$\underline{\text { Introduction }}$}

1983 is not only the 10oth anniversary of the birth of otto warburg, but is also the 50th anniversary of the determination of the structure of the flavin chromophore by Kuhn and wagner-Jauregg (1930) and the 5oth anniversary of the isolation of the first flavoprotein, the old Yellow Enzyme of brewers bottom yeast (Warburg and Christian 1933). In the intervening 50 years, some 200 different flavoproteins have been recognized, making this one of the largest single groups of related enzymes. These enzymes function in the catalysis of key steps in virtually every metabolic pathway in all life forms. They catalyze a variety of different types of chemical reaction in which the flavin is intimately involved. With a few exceptions, where the role of the flavin is not clear, e.g., glyoxylate carboligase (Cromartie and walsh 1976) or oxynitrilase (Jorns 1980), flavoproteins carry out oxidationreduction reactions, where one substrate is oxidized and a second is reduced. For all these enzymes, each catalytic cycle consists of two distinct processes, the acceptance of redox equivalents from a reducing substrate and the transfer of these equivalents to an oxidized acceptor. Accordingly, catalysis is comprised of two separate halfreactions: (1) the reductive half-reaction where the flavin is reduced and (2) the oxidative half-reaction, where the reduced flavin is reoxidized. This feature is very convenient experimentally, since it is possible to study each half-reaction separately. In this way, it is generally possible to identify individual steps in each half-reaction, often with the determination of the absorption spectra of intermediates and the rate constants of their formation and decay. This information can then be combined and fitted to catalytic turnover data, sometimes even employing the spectral properties of the flavin itself to monitor enzyme catalytic turnover (Gibson et al. 1964).

The nature of the substrates involved in the two separate half-reactions has been used as the basis for a classification scheme for flavoenzymes. Thus, Hemmerich et al. (1977) have defined five broad classes of flavoenzymes:

1) Transhydrogenase, where two-electron equivalents are transferred along with the appropriate hydrogen ions, from one organic substrate to another.

2) Dehydrogenase-oxidase, where two-electron equivalents are transferred to the flavin from an organic substrate and molecular oxygen is the oxidizing substrate, being reduced to $\mathrm{H}_{2} \mathrm{O}_{2}$.

1 Department of Biological Chemistry, University of Michigan, Ann Arbor, Michigan 48109 , U.S.A.

2 Fakultät für Biologie, Universität Konstanz, D-7750 Konstanz, FRG 
3) Dehydrogenase-monooxygenase, where the flavin is reduced, generally by a reduced pyridine nucleotide, and where on oxidation with $\mathrm{O}_{2}$ in the presence of a cosubstrate one atom of oxygen is inserted into the cosubstrate, while the other is reduced to $\mathrm{H}_{2} \mathrm{O}$.

4) Dehydrogenase-electron transferase, where the flavin is reduced by $2-e^{-}$ transfer from a reduced substrate and then reoxidized in sequential single electron transfers to acceptors, such as cytochromes and ironsulfur proteins.

5) Electron transferase, where the flavin is reduced and reoxidized in $1-\mathrm{e}^{-}$steps.

Model studies have shown that flavins are versatile catalysts, being able to be reduced and reoxidized in single- or 2-electron steps, being capable of forming adducts at various positions in the flavin ring system, and undergoing very facile photochemical reactions. A dramatic example of how this versatility is modulated and controlled by binding to specific proteins is the reactivity of various flavoproteins toward molecular oxygen. The free coenzyme in its reduced state reacts with $\mathrm{O}_{2}$ fairly rapidly and by a complex series of reactions involving flavin-oxygen adducts, flavin radicals, and the superoxide anion, $\mathrm{O}_{2}$, with the ultimate products being oxidized flavin and hydrogen peroxide (Gibson and Hastings 1962, Massey et al. 1973, Kemal et al. 1977). Flavoproteins, on the other hand, show very different responses to $\mathrm{O}_{2}$, depending on the particular class of enzyme. Some enzymes, such as those of the electron transferase class, react with $\mathrm{O}_{2}$ to generate almost quantitatively the blue flavin neutral radical, and $\mathrm{O}_{2}^{-}$. This reaction may be quite fast as in the case of flavodoxin (Massey et al. 1969); it is generally the second 1-electron oxidation of the semiquinone by $\mathrm{O}_{2}$ which is slow and which accounts for the overall slow catalytic reaction of such enzymes with $\mathrm{O}_{2}$. In another group of enzymes, the oxidases, the overall reaction with $\mathrm{O}_{2}$ is fast. In all cases examined of simple, nonmetal containing oxidases, there is no evidence for formation of either $\mathrm{o}_{2}^{-}$or flavin semiquinone; the reaction seems to go smoothly and monophasically to the products, $\mathrm{H}_{2} \mathrm{O}_{2}$ and oxidized flavin (Massey et al. 1969). In a third group of enzymes, the monooxygenases, the ability of the reduced flavin to react rapidly with $\mathrm{O}_{2}$ is retained, but now the oxygen molecule is utilized so that one atom is reduced to $\mathrm{H}_{2} \mathrm{O}$ and the other is incorporated into a primary substrate of the enzyme. All the enzymes of this class, which have been examined, share a common property; the first observed product in the oxidative half-reaction is a covalent adduct between flavin and $\mathrm{O}_{2}$, which has been identified as the flavin $\mathrm{C}(4 \mathrm{a})$-hydroperoxide (for a recent review, see Ballou 1982).

Over the years, it has become clear that members of each of these classes of flavoenzymes share other common properties in addition to their type of behavior towards $\mathrm{O}_{2}$. Thus, practically all members of the oxidase class form red flavin anion radicals on reduction by artificial reducing agents, but never by their normal substrates. They also readily form adducts with sulfite at the flavin $N(5)$-position and they all stabilize the benzoquinoid form of 8-mercaptoflavin, when the latter is incorporated into apoenzyme (Massey et al. 1979; Massey and Hemmerich 1980). Electron-transferase enzymes, on the other hand, generally stabilize the blue neutral flavin radical, do not form sulfite adducts, and exhibit the spectrum of the thiolate form of 8-mercaptoflavin. By contrast, flavoprotein monoxygenases, in general, do not stabilize any flavin radical form or any particular form of 8-mercaptoflavin, they fail to react with sulfite, and as already mentioned, all form observable flavin $\mathrm{C}(4 \mathrm{a})$-hydroperoxides with $\mathrm{O}_{2}$. It is clear that such common characteristics within a particular functional class of 
flavoproteins must reflect common features of protein structure in the flavin-binding pocket, which direct the versatile chemistry of the flavin coenzyme along particular paths. Current concepts of these structure-function relationships are based on studies of modified flavins and modified proteins and on the initial three-dimensional structures that have been determined for flavodoxins (Ludwig et al. 1982), for p-hydroxybenzoate hydroxylase (wierenga et al. 1979; wierenga et al. 1982), and for glutathione reductase (a C-S transhydrogenase) (Thieme et al. 1981; Schulz et al. 1982). In the case of Clostridium MP flavodoxin, the stabilization of the neutral semiquinone can be accounted for by hydrogen-bonding of the flavin N(5)H to a backbone carbonyl group of the protein (Ludwig et al. 1976); such H-bonding could account for the characteristics of electron transferases in general (Massey and Hemmerich 1980). In glutathione reductase, where the radical flavin is not stabilized, it is Lys 66 which makes the closest approach to N(5) (Schulz et al. 1982). Detailed structures are not yet available for any flavoprotein oxidases, but studies of chemically modified enzymes provide strong evidence that the common characteristics of the oxidases are imposed by a positively charged residue in the vi-

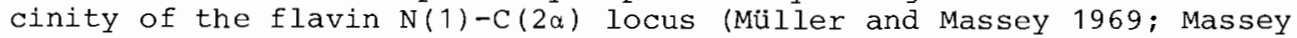
et al. 1979; Fitzpatrick and Massey 1983). Similarly, the observed stabilization of the flavin $\mathrm{C}(4 \mathrm{a})$-hydroperoxides in the case of flavin monooxygenases implies a common regiospecific interaction with the protein which is different from those in either the oxidases or the electron transferases. In the structure determined for the oxidized complex of p-hydroxybenzoate hydroxylase with substrate (wierenga et al. 1979), the substrate orientation is reasonable for attack by a c(4a) hydroperoxide, but the structure does not offer definitive evidence for the way in which the protein controls the oxygen reactivity of the flavin. The most informative structure would be that of the reduced enzyme-substrate complex, which is the form that reacts with oxygen to form the flavin hydroperoxide (Entsch et al. 1976a); unfortunately, one cannot extrapolate too much from the oxidized enzyme structure, since it is clear that a substantial conformational change occurs on substrate binding and probably also on reduction (Wierenga et al. 1979; Claiborne et al. 1982).

\section{General Considerations of Flavin-Protein Interactions}

Most of the binding energy in the interaction of the flavin coenzyme with its specific protein is associated with the side chain at position $N(10)$. Thus, flavoproteins in general are specific for binding either FMN or FAD and will generally accommodate artificial flavins with a number of structural modifications in the isoalloxazine ring system just as readily as the native flavin. But while it is the $N(10)$ side chain which provides the main anchor to the protein, the type of reaction catalyzed by the particular protein must be determined by specific interactions of the protein with the isoalloxazine ring system. This is illustrated in scheme 1, where possible hydrogen bonding positions between the flavin and protein or possible charge interactions, are indicated.

The pyrimidine ring of oxidized flavins contains the structural elements of barbituric acid or alloxan and is strongly electron deficient. The amide functions, $\mathrm{N}(1)-\mathrm{C}(2) \mathrm{O}, \mathrm{N}(3) \mathrm{H}-\mathrm{C}(4) \mathrm{O}$ (and also to a much smaller extent $\mathrm{N}(5)$ of the central pyrazine ring) provide sites for $\mathrm{H}$-bonding interactions with appropriate groups in the protein. From 2-electron reduction, the resulting 1,5-dihydroflavin has in addition, an ionizable function, $\mathrm{N}(1) \mathrm{H}$, with a $\mathrm{pK}$ in the region of 7 (Dudley et al. 1964). In the course of dehydrogenation of certain carbonyl-containing 




Scheme 1. Positions of possible flavin-protein hydrogen bonding (....) or of charge interactions (arrows)

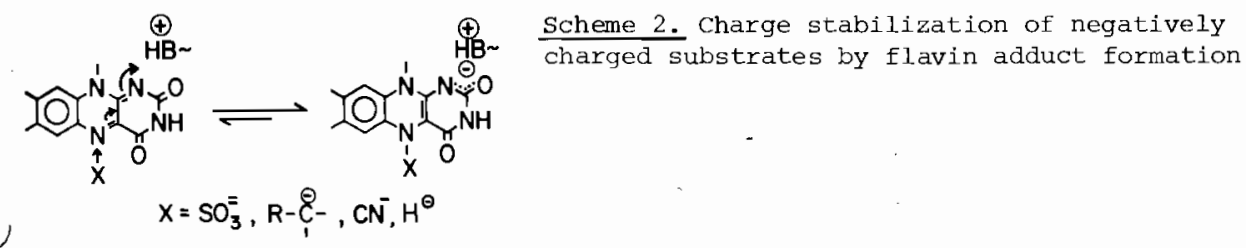

substrates, the abstraction of the substrate $\alpha$-proton by a protein base generates a negatively charged (carbanion) transition state. This negatively charged species, with a very high pK, can interact with oxidized flavin to form a negatively charged reduced molecule (Ghisla and Massey 1980). The flavin thus plays the role of a charge sink in the stabilization of this negatively charged transient (Scheme 2).

The middle pyrazine ring with its free electron pair at $N(5)$ has scarcely any basic function $(\mathrm{p} K<0)$ and in the oxidized state therefore cannot have any strong interaction with the protein. This position is on the other hand electrophilic. The presence of a positive charge in the neighborhood of $\mathrm{N}(1) \mathrm{C}(2) \mathrm{O}$ enhances the electrophilic character of position $\mathrm{N}(5)$ and makes it much more susceptible to attack by a nucleophile X (Massey et al. 1969; Müller and Massey 1969). In model systems, $X$ can be for example, sulfite (Müller and Massey 1969), phosphines (Müller 1972), cyanide (Jorns 1980), borohydride (Müller et al. 1969); in biochemical systems, it can be a hydride equivalent, sulfite or a carbanion (Massey et al. 1979; Ghisla and Massey 1980; Scheme 2).

The one-electron reduction of flavins yields the radical $\mathrm{HF}^{-}{ }^{-}$. The position $\mathrm{N}(5)$ of this species is some 10 orders of magnitude more basic $(\mathrm{p} K \sim 8$ ) than it is in F1ox (Ehrenberg et al. 1967; land and Swallow 1969). With this function, the radical (and the fully reduced flavin) has an added possibility of being stabilized by hydrogen bonding to the protein. In the case of flavodoxin, such an effect is the apparent cause of thermodynamic stabilization of the blue neutral radical (Ludwig et al. 1976; see scheme 3). On the other hand, the existence of a protein positively charged group in the vicinity of the $\mathrm{N}(1) \mathrm{C}(2) \mathrm{O}$ region would be expected to stabilize the red anion radical,
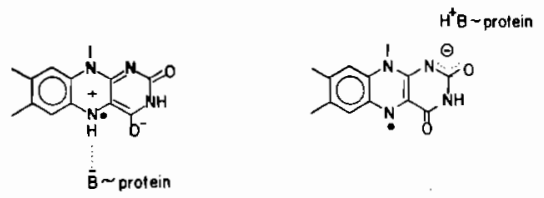

Scheme 3. Modes of protein stabilization of neutral and anionic flavin radicals 
thus explaining the finding that all flavoproteins, which form $N(5)$ sulfite adducts (see Scheme 2), also stabilize the anion radical (Massey et al. 1969; Müller 1972; Massey et al. 1979; Scheme 3).

Specific interactions of the protein with the aromatic xylene ring are rarely invoked in discussion of flavoprotein properties. The 8methyl group is of course frequently employed in forming a covalent linkage of the flavin to the protein, where histidyl, tyrosyl, and cysteinyl derivatives have been found (Edmondson and Singer 1976). These groups can directly affect the chemical properties of the isoalloxazine nucleus and also offer the possibility of secondary charge and hydrogen bonding interactions with the protein. But in terms of noncovalent interactions, the dimethyl benzene portion of the flavin would be restricted primarily to hydrophobic or charge transfer interactions.

Mechanisms of Flavoprotein Catalysis

Dehydrogenation Reactions (The Reductive Half-Reaction)

In a biochemical sense, the term "dehydrogenation" means the breaking of two bonds involving hydrogen in the system XH-YH and the transfer of two electrons (and protons) to an acceptor, A.

$$
\mathrm{XH}-\mathrm{YH}+\mathrm{A} \rightleftharpoons \mathrm{X}=\mathrm{Y}+\mathrm{AH}_{2}
$$

The acceptor $A$ in our case if $F 1$ ox. According to the chemical nature of the substrate, the mechanism of the dehydrogenation reaction will be distinct. We can categorize the following types of substrate dehydrogenations (Scheme 4).

\section{FLAVIN-DEHYDROGENATION SUBSTRATES} a)PYRIDINE NUCLEOTIDES

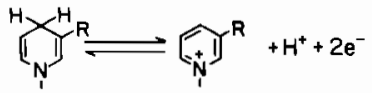

b) ACTIVATED SUBSTRATES

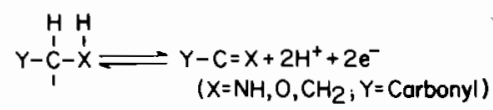

c) "NON-ACTIVATED" SUBSTRATES

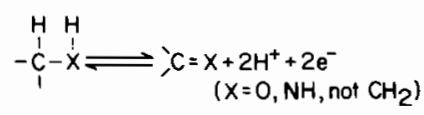

\section{d) SULFHYDRYL SUBSTRATES}

$\mathrm{R}-\mathrm{SH}+\mathrm{HS}-\mathrm{R} \rightleftharpoons \mathrm{R}-\mathrm{S}-\mathrm{S}-\mathrm{R}+2 \mathrm{H}^{+}+2 \mathrm{e}^{-}$
Scheme 4. Types of substrates oxidized by flavin enzymes, classified according to their chemical properties. "Nonactivated" substrates denotes substrates which cannot stabilize $\alpha$-carbanions by delocalization

The mechanisms for the dehydrogenation reactions of the first two classes are of special interest. The following entirely different mechanisms are possible for these reactions (Scheme 5). 
(i) HYDRIDE TRANSFER

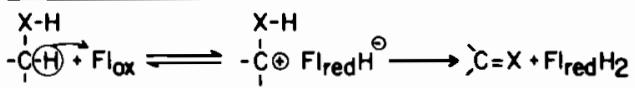

(ii) RADICAL TRANSFER

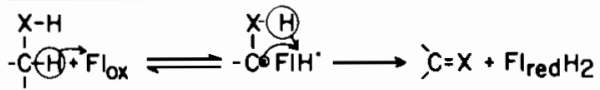

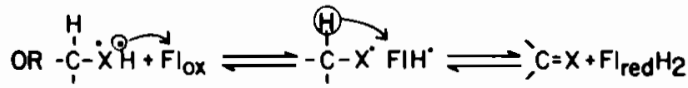

Scheme 5. Chemical mechanisms for the oxidation of substrates containing kinetically stable $\mathrm{C}-\mathrm{H}$ bonds. Note that mechanisms (i) and (iii) can be combined to yield a carbanion initiated hydride transfer, cf. also scheme 11

(iii) CARBANION MECHANISM, GROUP TRANSFER

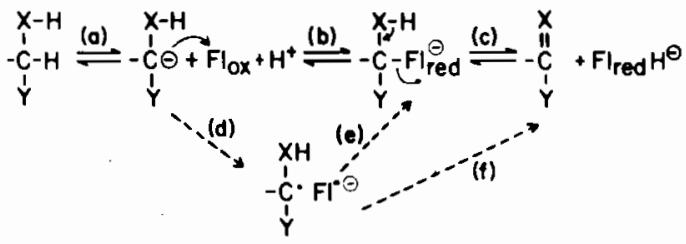

Pyridine Nucleotides

In the case of reversible dehydrogenation of reduced pyridine nucleotide, the present evidence is strongly in favor of direct transfer. of a hydride equivalent between the C(4) $\mathrm{H}$ of the pyridine nucleotide and the flavin N(5)-position, according to mechanism (i) (Brustlein and Bruice 1972; Walsh 1979). The earlier mechanism studies are strongly supported by the crystallographic data on glutathione reductase, which show that the positions $\mathrm{N}(5)$ of the oxidized flavin and $\mathrm{C}(4) \mathrm{H}$ of NADPH are precisely in the position for such a transfer (Pai and Schulz 1982; Scheme 6). Such a juxtaposition is essential for a hydride transfer mechanism, in contrast to a radical mechanism, where orbital overlap between flavin and pyridine nucleotide would need to be much less restrictive. The same crystallographic data with glutathione reductase also show that the flavin and pyridine nucleotide ring systems are juxtaposed in an approximately parallel fashion, as was predicted from the earlier observations of charge transfer complexes in pyridine nucleotide-flavoprotein interactions (Massey and Ghisla 1974).
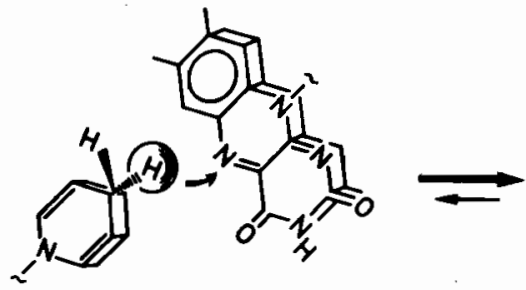

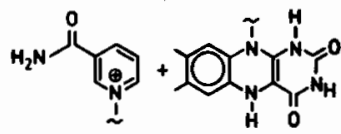

Scheme 6. Hydride transfer between pyridine nucleotides and flavins. Note that the hydrogen to be transferred as hydride must be located above or below the flavin plane, juxtaposed to the flavin $\mathrm{N}(5)$ 
The oxidation of substrates with electron withdrawing activating groups adjacent to the position of dehydrogenation appear to be initiated by the abstraction of the relatively acidic $\alpha$-proton (Porter et al. 1973; Ghisla and Massey 1980). This is in accord with the finding that substrate analogs which have a good leaving group in the position $\beta$ - to the oxidizing $\mathrm{C}-\mathrm{H}$ function, e.g., halogen, in many cases are capable of undergoing enzyme catalyzed elimination reactions (Walsh et al. 1971; Walsh et al. 1973a, 1973b). This is easily envisaged as a side reaction running parallel to the normal catalytic one (Scheme 7).

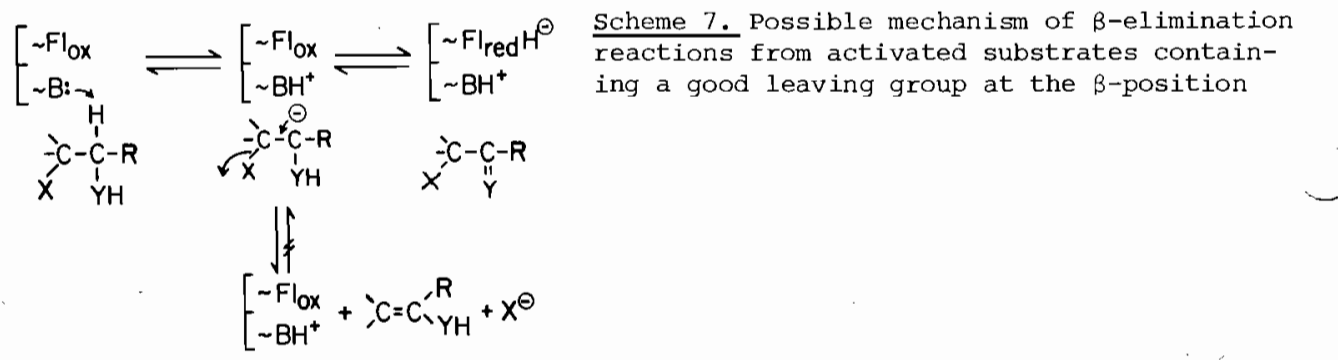

Following the initial event of proton abstraction, several routes are possible for the formation of the final products, as illustrated in Scheme 5, mechanism (iii). The carbanion may make a direct nucleophilic attack at the flavin N(5)-position to yield a covalent adduct on the route to reduced flavin and oxidized substrate (reactions iii b and c). Alternatively, the reaction could proceed via the radical mechanism (iii d) to yield a radical pair, which could react further, either to collapse into the covalent intermediate or by $1 e^{-}$transfer yield directly the overall products of the reaction.

In the special case of $\alpha-\beta$-oxidation of acyl substrates by acyl CoA dehydrogenases and possibly also of succinate by succinate dehydrogenase, the reaction sequence appears to involve a hydride transfer initiated by deprotonation of the substrate at the $\alpha$-position (combination of sequences iii a) and (i), Scheme 5). This hypothesis is supported by the following experimental evidence with acyl CoA dehydrogen ases:

a) Bacterial butyryl COA dehydrogenase was found (Fendrich and Abeles 1982 ) to catalyze the $2 \rightarrow 4$ tautomerization of vinylacetyl CoA to crotonyl COA (Scheme 8)

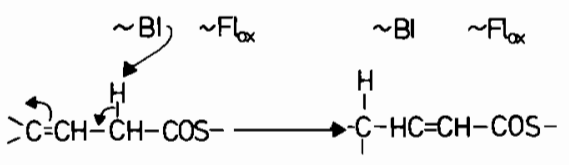

$2 \rightarrow 4$ Isomerisation
Scheme 8. Tautomerization of vinylacetyl thioester to crotonyl thioester catalyzed by butyryl CoA dehydrogenase. (From Fendrich and Abeles 1982) 
b) B-Fluoro-substituted acyl CoAs eliminate fluoride in the presence of butyryl COA dehydrogenase without the enzyme apparently undergoing reduction (cf. Scheme 7) (Fendrich and Abeles 1982).

c) 3-Pentynoyl pantetheine is first isomerized by the bacterial enzyme to 2,3 pentadienoyl pantetheine, which subsequently leads to irreversible inactivation (Fendrich and Abeles 1982; Frerman et al. 1980; Scheme 9).



Scheme 9. Inactivation of butyryl CoA dehydrogenase by pentynoyl pantetheine. (From Fendrich and Abeles 1982)

d) 3,4 Pentadienoyl COA is converted to the 2,4-tautomer by pig kidney general acyl COA dehydrogenase (Wenz et al. 1982; Scheme 10).<smiles>C=C=CC(CCBr)C(=O)SSC=CCOC(C)C=CC(=O)S</smiles>

Scheme 10. Tautomerization of 3,4-pentadienoyl COA to the 2,4 -isomer by general acylCoA dehydrogenase

The sum of this evidence leads to the firm conclusion that catalysis is initiated by proton abstraction from the $\alpha$-carbon of the substrate. For elucidating the rest of the mechanism, the normal coenzyme, FAD, was replaced by reduced 5-deaza-FAD, tritium-labelled at position $C(5)$. This replacement of coenzyme was necessary in order to prevent exchange of hydrogen from the flavin 5-position with solvent protons. Incorporation of one $3 \mathrm{H}$-equivalent into crotonyl CoA to form 3 ( $3 \mathrm{H})-$ butyryl CoA was found (Ghisla, unpublished). The stereochemistry of the oxidation of butyryl CoA by normal enzyme was found to be $2(R)$, 3(R) (antiperiplanar) (Bielemann and Hirt 1970; LaRoche et al. 1971; Kawaguchi et al. 1980). Thus, the mechanism of Scheme 11 can be proposed, which is also in agreement with the large isotope effects observed by Reinsch et al. (1980).

In the case of dehydrogenation of substituted carboxylic acids such as a-amino or a-hydroxy acids, the catalytic sequence is also initiated by the abstraction of the $\alpha$-hydrogen as a proton, according to step (iii a) of Scheme 5. The substrate carbanion-F1ox pair created during the transition state can collapse into a covalent $N(5)$ adduct, which then fragments into the products. This reaction sequence has been shown directly during the oxidation of glycollate by lactate oxidase (Ghisla and Massey 1980) and is illustrated in scheme 12. 

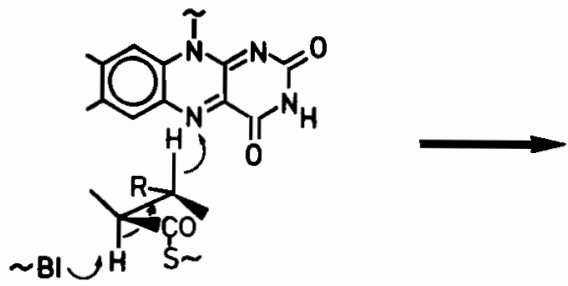

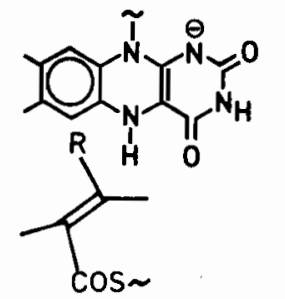

Scheme 11. Mechanism of $\alpha-\beta$ oxidation catalyzed by acyl COA dehydrogenase

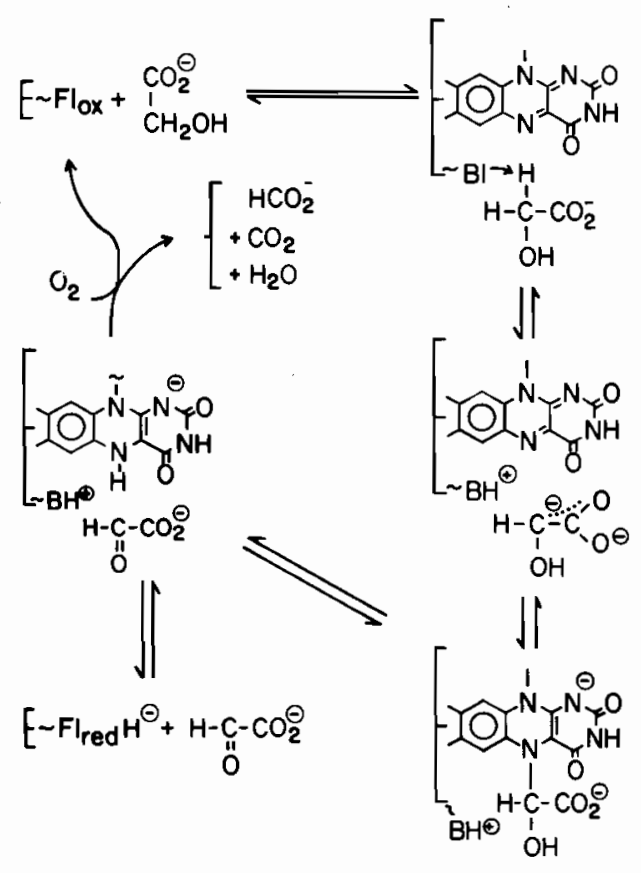

Scheme 12. Mechanism of substrate oxidation by lactate oxidase involving carbanion and covalent adduct formation. The sequence shows the oxidation of glycollate

A similar mechanism is favored strongly for D-amino acid oxidase. While the direct formation of a flavin $N(5)$-substrate adduct has not been demonstrated for any natural substrate, it has been shown in the case of the enzyme-catalysed oxidation of nitroalkane carbanions (Porter et al. 1973). This enzyme has been the subject of intensive mechanistic study by several groups over the years (Massey and Gibson 1963; Walsh et al. 1971; Porter et al. 1973); its amino acid sequence has recently been determined (Ronchi et al. 1982) and specific active site residues identified (Swenson et al. 1982, 1983). These are illustrated diagrammatically in Scheme 13. Its mechanism and the role played by specific protein residues may be envisaged as shown in scheme 14 .

Of particular interest is the role played by an arginine residue shown in the above scheme. An active site arginine residue was discovered by Ferti et al. (1981) by reaction of the enzyme with cyclohexanedione. We have found that when enzyme is modified in this way and the native flavin, FAD, is replaced by 8-mercapto-FAD, the spectrum of the resulting 8-mercapto-FAD enzyme is dramatically different from that of unmodified enzyme containing 8-mercapto-FAD (Fitzpatrick and Massey 1983). 


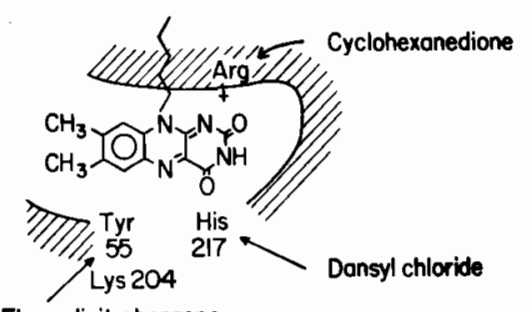

Fluorodinitrobenzene
Scheme 13. Active site of D-amino acid oxidase

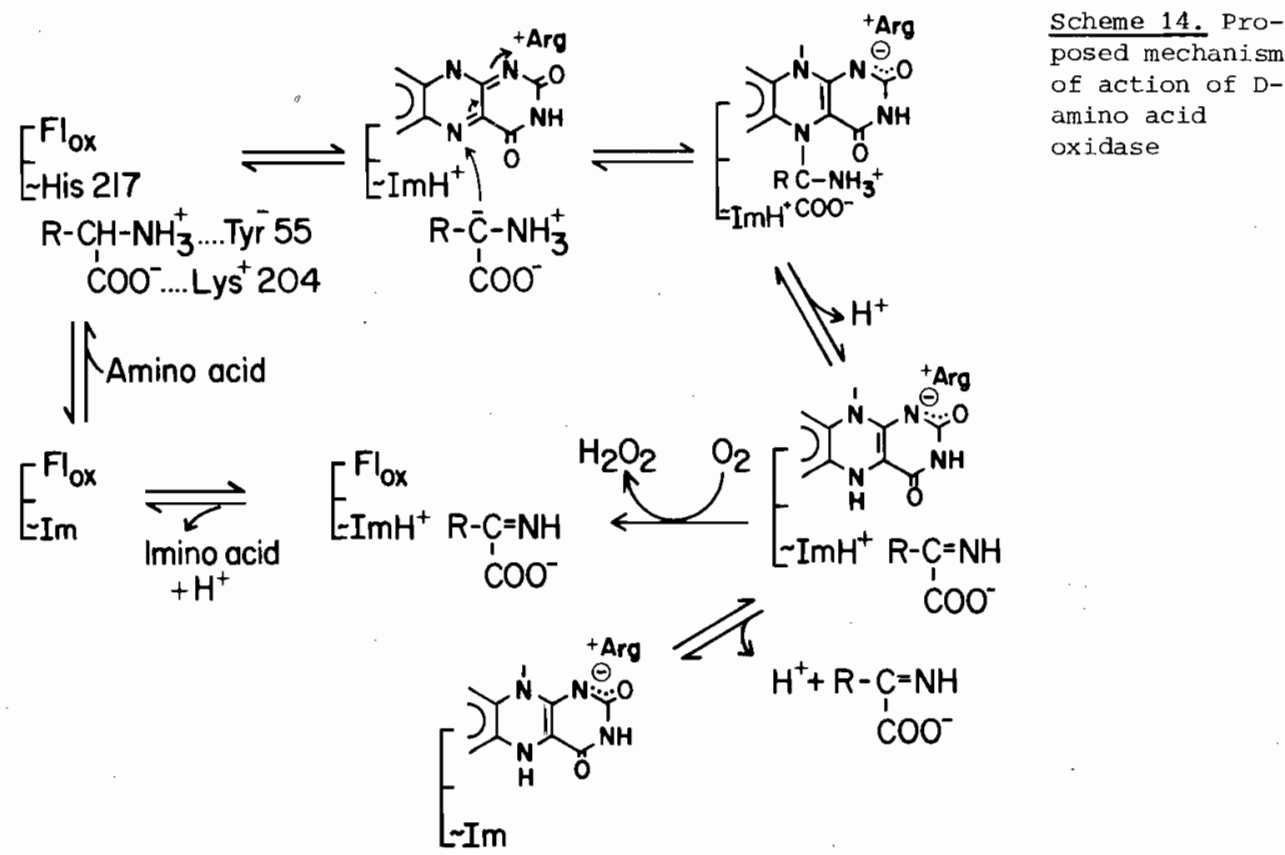

This is illustrated in Fig. 1. The absorption maximum at $595 \mathrm{~nm}$ of the unmodified 8-mercaptoflavin enzyme is typical of that found with other oxidases and is postulated as being due to stabilization of the benzoquinoid form of 8-mercaptoflavin by a positively charged protein residue in the vicinity of the flavin $\mathrm{N}(1) \mathrm{C}(2 \alpha)$ region (Massey et al. 1979; Massey and Hemmerich 1980).

This residue has also been postulated as playing an important role in the attack of nucleophiles, such as substrate carbanions and sulfite, at the flavin $\mathrm{N}(5)$ position and for stabilization of the anionic flavin semiquinone (cf. Schemes 2 and 3 ). These hypotheses are strongly supported by the results with cyclohexanedione-modified D-amino acid oxidase. With the active site arginine modified, the spectrum of the 8-mercapto-FAD enzyme now shows a maximum at $535 \mathrm{~nm}$, typical of the 8-thiolate form of the flavin (Fitzpatrick and Massey 1983). Furthermore, it has been found that flavoprotein oxidases containing 8-mercapto-FAD all form $\mathbf{N}(5)$-sulfite adducts just like the native flavin enzymes. On the other hand, nonoxidase flavoenzymes, which lack the inductive effect of the positive charge around the flavin $\mathrm{N}(1) \mathrm{C}(2 \alpha)$ region, do not form sulfite adducts. However, when the native flavin of these enzymes is replaced by 8-mercaptoflavins, sulfite is found 


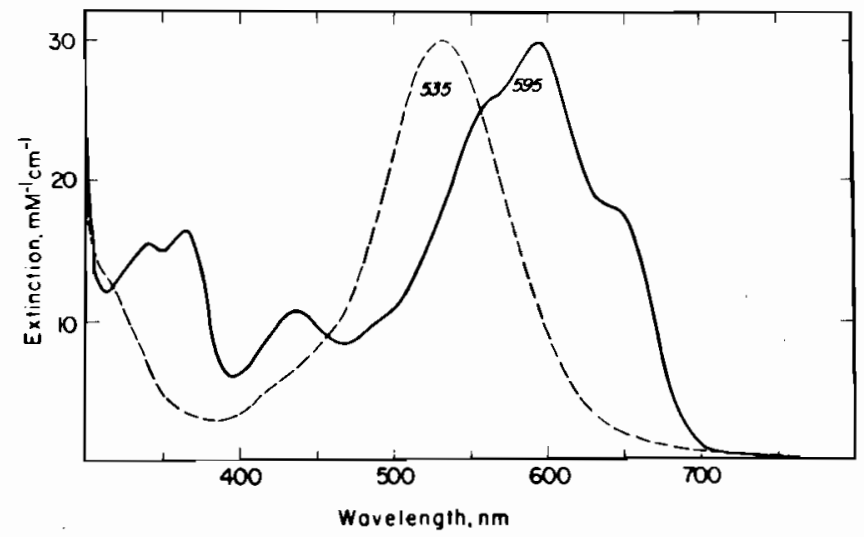

Fig. 1. Effect of cyclohexanedione modification of D-amino acid oxidase on the spectrum of enzymebound 8-mercapto-FAD. Solid line, 8-mercaptoFAD bound to unmodified enzyme. Dashed Zine, 8mercapto-FAD bound to cyclohexanedione modified enzyme (From Fitzpatrick and Massey, 1983)

to react irreversibly, eliminating the thiol function and forming 8sulfonylflavins. With cyclohexanedione-modified D-amino acid oxidase, sulfite now reacts in a similar fashion; instead of forming an $N(5)-$ sulfite adduct as with the unmodified enzyme, it now reacts irreversibly to form the 8-sulfonyl-FAD enzyme (Fitzpatrick and Massey 1983).

\section{"Nonactivated" Substrates}

The mechanisms of dehydrogenation of "nonactivated" substrates, such as alcohols and amines, are still largely unsettled experimentally. In these cases, the abstraction of the a-hydrogen to form a carbanion is unlikely, since such a carbanion would require a large activation energy for its formation. In the case of monoamine oxidase, Silverman et al. (1982) therefore suggested a radical mechanism similar to that of equation (ii) of Scheme 5. The reaction for dehydrogenation of amines as formulated by Silverman is shown (Scheme 15).

An analogous reaction scheme probably applies in the case of oxidation of alcohols by flavoproteins. It is noteworthy that most alcohol oxidase preparations show a variable, but generally high content of stable anionic flavin radical (Geissler and Hemmerich 1981; Mincey et al. 1980). However, this radical form is catalytically inactive and it

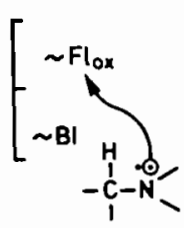

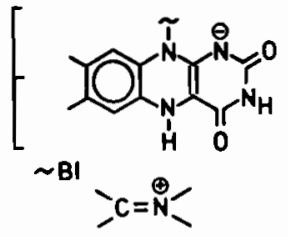<smiles>Cc1cc2c(cc1C)N(C)C1C(=O)NC(=O)N=C1N2C</smiles>

Scheme 15. Mechanism of oxidation of "Ionactivated" substrates, as shown for the oxidation of an amine by monoamine oxiōase. (From Silvermann et al. 1982) 
would seem likely that it originates as a side reaction of catalysis, possibly due to a finite rate of dissociation of substrate radical from the substrate radical-flavin radical pair as a competing reaction to the collapse of the radical pair to yield aldehyde and reduced flavin.

It should be emphasized, however, that up to now no compelling arguments against a hydride mechanism have been advanced. Therefore, while we think that a radical mechanism is more likely, the possibility of oxidation of amines and alcohols proceeding via a hydride mechanism cannot be dismissed.

\section{Thiol-Disulfide Substrates}

The reversible oxidation-reduction reactions of thiol-disulfide pairs, such as lipoic acid, glutathione, and thioredoxin have been examined extensively in several laboratories, notably that of williams (1976). An important factor for the understanding of this group of flavoproteins was the discovery of an internal redox active disulfide of the protein, which is in contact with the flavin, and mediates the transfer of redox equivalents between the thiol-disulfide substrate and the enzyme bound flavin (Searls 1960; Massey and Veeger 1960; Massey and Williams 1965; Zanetti and Williams 1967; Fox et al. 1982). The reaction catalyzed by 1 ipoyl dehydrogenase as postulated by Arscott et al. (1981) is shown in part in Scheme 16. Dihydrolipoic acid reduces the active site disulfide via formation of a mixed protein-substrate disulfide in a reaction involving proton abstraction from the dihydrolipoic acid by an active site base, believed to be a histidyl residue. Under the influence of bound $\mathrm{NAD}^{+}$, the proximal active site thiolate makes a nucleophilic attack on the flavin to form the covalent $C(4 a)$-adduct of structure 5. The distal thiolate anion then attacks the sulfur of the flavin adduct with reformation of the active center disulfide and leaving behind the reduced flavin (structure 7). The latter now participates in a hydride transfer to the bound pyridine nucleotide, as discussed earlier (Scheme 6). This mechanistic proposal is nicely supported by the $\mathrm{x}$-ray crystallographic studies on the closely related enzyme glutathione reductase, where all of the structural elements required for this mechanism are present ( $\mathrm{Pai}$ and Schulz 1982). Similarly, Loechler and Hollocher (1975) concluded from kinetic studies in model systems that $\mathrm{C}(4 \mathrm{a})$ adducts also occur during the oxidation of thiols by free flavins. In addition, with lipoyl dehydrogenase, a flavin $C(4 a)-S-R$ adduct was identified spectrally when NAD ${ }^{+}$was
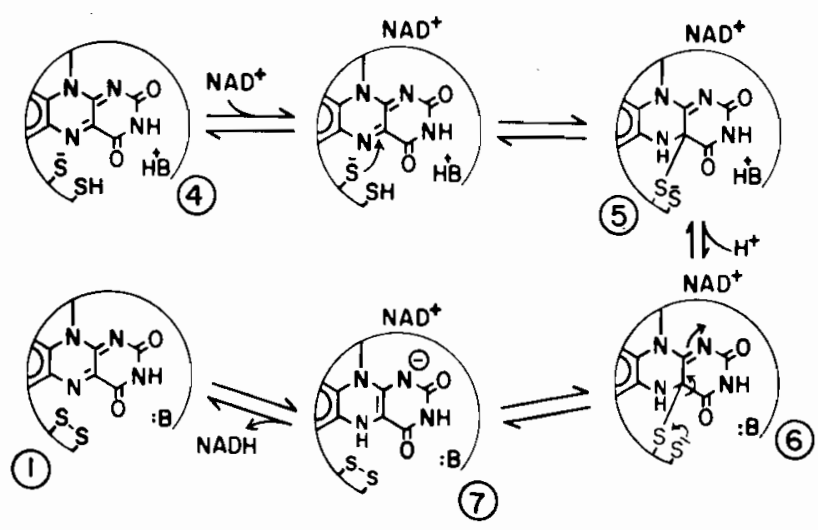

Scheme 16. Proposed mechanism of lipoyl dehydrogenase, showing the intermediate formation of a flavin-thiolate $C(4 a)$-adduct 
added to enzyme which was alkylated at one of its thiol functions (Thorpe and Williams 1981). This alkylation prevented frank electron transfer and so trapped this putative intermediate.

The Oxidative Half-Reaction

As indicated in the introduction, reduced flavoenzymes produced by the pathways already discussed, can complete their catalytic cycle in the oxidative half-reaction, by reaction with a variety of one-electron or two-electron acceptors. The nature of the oxidizing substrate is specific to the particular enzyme, as indicated in the classification scheme shown in the introduction. The crossover between two-electron and one-electron transfer, which is a biochemical phenomenon restricted almost entirely to flavin enzymes, is a subject which has not yet received the same depth of experimental investigation as the simple two-electron transfers, which have been discussed here. In this review, we are restricting our coverage of the oxidative half-reaction to that of reduced flavins and flavoproteins with molecular oxygen. For reviews of the role of flavin in $2 e^{-/ 1 e^{-}}$crossover, see Kamin and Lambeth 1982; Hemmerich et al. 1982 .

The Activation of Molecular Oxygen

Flavins are one of the few catalysts used by living cells which have the capacity to activate molecular oxygen. In its reaction with reduced $\mathrm{flavin}, \mathrm{O}_{2}$ can be reduced to the $1 \mathrm{e}^{-}$reduced state, superoxide anion $\left(\mathrm{O}_{2}^{-}\right)$, to the $2 \mathrm{e}^{-}$reduced state, peroxide $\left(\mathrm{H}_{2} \mathrm{O}_{2}\right)$, or to the $4 \mathrm{e}^{-}$ reduced state, $\mathrm{H}_{2} \mathrm{O}$. In the case of flavoproteins, the inherent reactivity of the singlet reduced flavin molecule with triplet $\mathrm{O}_{2}$ is modulated in various ways, as described in the introduction, and has long served as a basis for useful differentiation of flavoenzymes into broad classes.

Impressive progress has been made in the last few years in the elucidation of the primary steps in the reaction of the reduced flavin with $\mathrm{O}_{2}$. The results of early rapid reaction kinetic studies with free flavins had indicated the existence of oxygenated flavin species in the overall reaction (Gibson and Hastings 1962; Massey et al. 1973; Kemal et al. 1977). The first decisive evidence for such intermediates came from studies with flavoprotein monooxygenases, where species with absorbance maxima near $400 \mathrm{~nm}$ were observed as transients in the reaction with $\mathrm{O}_{2}$ of reduced p-hydroxybenzoate hydroxylase (Spector and Massey 1972) and melilotate hydroxylase (Strickland and Massey 1973) and as a stable isolatable species in the case of bacterial luciferase (Hastings et al. 1973). In all cases, based on comparison with spectra of known flavin derivatives, these intermediates were proposed to be the flavin C(4a)-hydroperoxide (Ghisla et al. 1977). The unequivocal proof of the structure of this hydroperoxide was achieved by means of 13 C-NMR spectroscopy where the C(4a)-position of FMN was enriched with $13 \mathrm{C}$ and the stable hydroperoxide of bacterial iuciferase studied (Ghisla et al. 1978).

The mechanism of formation of the hydroperoxide is now generally agreed to result via a radical mechanism as illustrated in Scheme 17.

$$
\mathrm{F} 1 \mathrm{red}^{\mathrm{H}^{-}}+\uparrow \mathrm{O}_{2} \uparrow \rightleftharpoons\left[\mathrm{F} 1 \mathrm{H}^{*} \uparrow \uparrow \mathrm{O}_{2}^{-}\right] \rightleftharpoons\left[\mathrm{F} 1 \mathrm{H}^{-} \downarrow \uparrow \mathrm{O}_{2}^{--}\right] \rightleftharpoons \mathrm{F} 1 \mathrm{H}-\mathrm{OOH}
$$

Scheme 17. Mechanism of formation of flavin $c(4 a)$-hydroperoxide 
First a one-electron transfer occurs to form a flavin radical-superoxide pair having parallel spins. After spin inversion, which is supposed to be the rate-limiting step, the biradical pair collapses to form the flavin C(4a)-hydroperoxide, as expected from the spin density of the flavin radical (Platenkamp et al. 1980). In model studies, the pair of radicals, $\mathrm{F}_{1 \mathrm{H}}{ }^{-}$and $\mathrm{O}_{2}^{-}$, generated by pulse radiolysis, has been shown to collapse into the hydroperoxide (Anderson 1982). Similar conclusions have been reached by Nanni et al. (1981). While the collapse of the radical pair is very rapid, it clearly can form the $\mathrm{C}(4 \mathrm{a})-\mathrm{hy}-$ droperoxide only when this position of the flavin is unimpeded by the surrounding protein. Recent studies with chemically reactive flavins (5-deazaflavin and 4-thioflavin) substituted for the native flavin suggest strongly that with electron transferases, the flavin region $N(5)-C(4 a)-C(4)$ is rather inaccessible to solvent-borne reagents, as illustrated in Scheme 18 (Schopfer, Claiborne, Detmer, and Massey, unpublished). Therefore, the possibility is very real that in this group of enzymes, the flavin hydroperoxide does not form and that the radical pair $\mathrm{F} 1 \mathrm{H}^{\circ} \mathrm{O}_{2} \mathrm{H}^{*}$ instead largely dissociates into the free flavin radical and $\mathrm{O}_{2}^{-}$, the experimentally observed products of this group of enzymes.

\section{ELECTRON TRANSFERASES}



OXIDASES

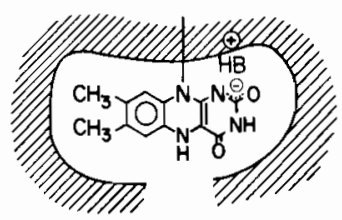

Scheme 18. Active site topography of different classes of flavoproteins, as determined by replacement of the native coenzymes with flavins containing chemically reactive substituents

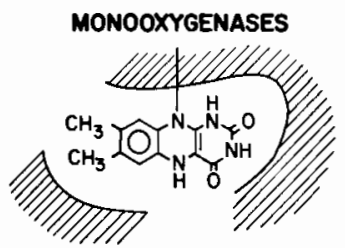

\section{Oxidases}

On the other hand, oxidases, by virtue of their known reactivity with substrates, substrate analogs, and sulfite, clearly have their flavin exposed in this critical region. In this class, the formation of the flavin $\mathrm{C}(4 \mathrm{a})$-hydroperoxide is thus feasible, although it must be emphasized that in no case has it yet been observed experimentally. However, this may be simply for kinetic reasons. Bruice and colleagues have found that even with the chemically stabilized $N(5)$-substituted $\mathrm{C}(4 \mathrm{a})-f l a v i n$ hydroperoxides, the stability is limited to apolar solvents; in aqueous solution, the hydroperoxides break down rapidly at neutral $\mathrm{pH}$ to yield $\mathrm{H}_{2} \mathrm{O}_{2}$ and oxidized flavin (Kemal and Bruice 1976). On the basis of the available evidence, we consider it likely that a similar sequence of reactions occurs with this group of enzymes, as illustrated in Schemes 18 and 19.

\section{Monooxygenases}

The third main group of flavoenzymes is the monooxygenases where the $\mathrm{O}_{2}$ molecule is cleaved, with one atom being incorporated into a substrate and the other converted to $\mathrm{H}_{2} \mathrm{O}$. Four main subclasses of this group can be differentiated. The first of these is sometimes known as 


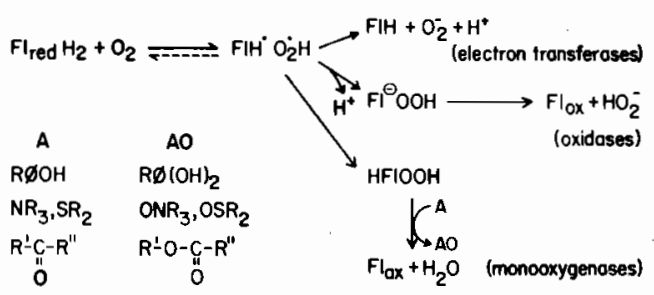

Scheme 19. Proposed explanation for the different types of reaction with $\mathrm{O}_{2}$ of flavoprotein electron transferases, oxidases, and monooxygenases

internal monooxygenases, because the source of reducing equivalents for reduction of the flavin is the substrate which is monooxygenated. This class is exemplified by L-lactate monooxygenase and L-lysine monooxygenase, which carry out oxidative decarboxylations of L-lactate to yield acetate, $\mathrm{CO}_{2}$ and $\mathrm{H}_{2} \mathrm{O}$, and of L-lysine to yield $\delta$-aminovaleramide, $\mathrm{CO}_{2}$ and $\mathrm{H}_{2} \mathrm{O}$. However, convincing evidence has been produced that. these enzymes belong better to the oxidase class of flavoproteins, being in fact "adventitious" monooxygenases, because the normal oxidase products, $\mathrm{H}_{2} \mathrm{O}_{2}$ and the corresponding keto and imino acids, do not diffuse rapidly from the enzyme surface, and there proceed to react to produce the oxidative decarboxylations typical of keto and imino acids with $\mathrm{H}_{2} \mathrm{O}_{2}$ free in solution (Lockridge et al. 1972).

The remaining "true" monooxygenases (see Scheme 19) all share the common property of requiring an external source of reducing equivalents to produce the reduced flavin, which subsequently reacts with $\mathrm{O}_{2}$ and the substrate which is oxygenated. This third substrate is in all cases either NADH or NADPH. There appear to be mechanistically two different types. The largest and most studied group are the so-called aromatic or phenolic hydroxylases, where the substrate is an unsubstituted or substituted phenolic compound and where a second hydroxyl group is introduced, generally ortho to the preexistent one. All of the enzymes of this class share certain common features, notable among which is the effector role of the substrate on the reduction of the enzyme flavin by pyridine nucleotide; the flavin is reduced $10^{3}-10^{5}$ times more rapidly by $\mathrm{NAD}(P) \mathrm{H}$ when the substrate is bound than it is when the substrate is absent (see Massey and Hemmerich, 1975 for a review). The other types of flavoprotein monooxygenase carry out oxygen transfer reactions typical of those carried out by organic peroxides in free solution, converting either nitrogenous or sulfur containing substrates to the corresponding $\mathrm{N}$-oxides or S-oxides, or inserting an oxygen atom into a preexisting ring system. Bacterial luciferase, which converts a long chain aldehyde to the corresponding carboxylic acid at the same time as emitting light also formally belongs in this group. This group of enzymes lacks the effector role of the substrate displayed by the phenolic hydroxylases; the rate of flavin reduction by $\mathrm{NAD}(\mathrm{P}) \mathrm{H}$ is uninfluenced by prior substrate binding (Beaty and Ballou 1981a; Ryerson et al. 1982).

With all groups of "true" monooxygenases, the first observed product of reaction of $\mathrm{O}_{2}$ with the reduced flavin is the $\mathrm{C}(4 \mathrm{a})$-hydroperoxide. In the case of the phenolic, hydroxylases, this is a transient species, requiring rapid reaction studies for its detection and generally requiring the presence of an effector for its (partial) stabilization. With the other monooxygenases, however, the flavin $c(4 a)$-hydroperoxide is generally remarkably stable and usually requires the presence of oxygenatable substrate to be discharged rapidly. 
As might be expected, both from the different properties exhibited by each group of oxygen activating flavoenzymes, as well as from the different types of reactions catalyzed, these enzymes appear to operate by distinctly different mechanisms. The most studied, and still not completely understood, are the reactions catalyzed by the phenolic hydroxylases. Soon after the initial discovery of the flavin $\mathrm{C}(4 \mathrm{a})-$ hydroperoxide with p hydroxybenzoate hydroxylase (Spector and Massey 1972), it was recognized that two other distinct intermediates were involved in the oxygenation reaction and their spectra determined (Entsch et al. 1974, 1976a). The third intermediate has a spectrum similar to that of the hydroperoxide and as rapid quench studies showed that oxygen atom transfer to substrate had already occurred at the stage of intermediate II (Entsch et al. 1974), the structure of intermediate III could logically be ascribed to that of the $C(4 a)$-hydroxyflavin, which by elimination of $\mathrm{H}_{2} \mathrm{O}$, would yield oxidized flavin ready for the next cycle of catalysis. The structure of intermediate II has remained without satisfactory explanation and so the details of the catalytic mechanism have remained incomplete. Entsch et al. (1976a) proposed the mechanism shown in scheme 20 , which involves nucleophilic attack by the delocalized electrons of the phenolate ion on the terminal oxygen of the hydroperoxide. Cleavage of the O-O-bond is synchronous with formation of a ring-opened form of the flavin and the cyclohexadienone tautomer of the product. The ring-opened flavin next recloses to form the pseudobase, C(4)-hydroxyflavin (intermediate III), while the oxygenated substrate rearomatizes. Finally $\mathrm{H}_{2} \mathrm{O}$ is split out from the hydroxyflavin and oxidized enzyme is regenerated. This step, in which the product is also released from the enzyme, is generally the rate-limiting step in catalysis. In the above formulation, intermediate II, which in the case of p-hydroxybenzoate hydroxylase has

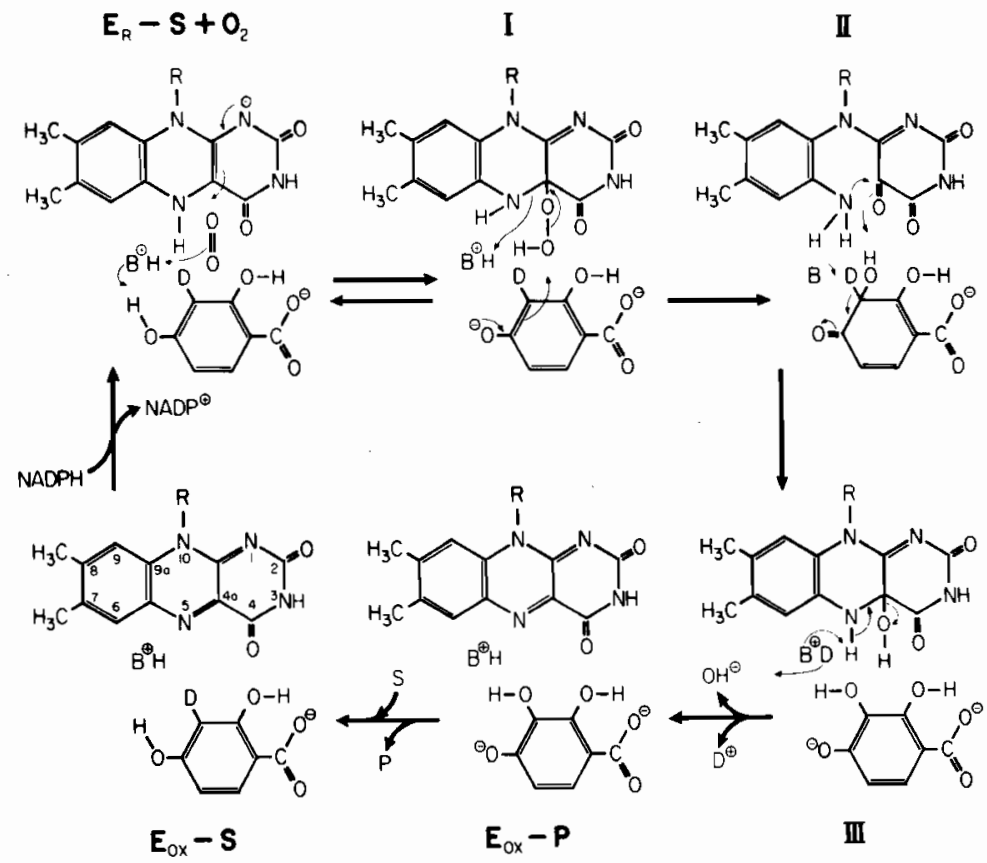

Scheme 20. Proposed mechanism for p-hydroxybenzoate hydroxylase. (From Entsch et al. 1976a) 
<smiles></smiles><smiles>[H][Y]1([H])c2cc(I)c(C)cc2N(C)C2=NC(=O)N=C(O)C21O</smiles><smiles>C=C</smiles><smiles>C1=CC=C1</smiles><smiles>Cc1cc2c(cc1C)N(C)C1(O)C(=O)NC(=O)N=C1N2C</smiles>

$\lambda_{\max } 342 \mathrm{~nm}$

$\varepsilon=7100 \mathrm{M}^{-1} \mathrm{~cm}^{-1}$

solvent $\mathrm{CH}_{3} \mathrm{CN}$<smiles>Cc1cc2c(cc1C)N(O)C1(O)C(=O)N=C(O)N=C1N2C</smiles>

Scheme 21. Model for the ringopened flavin proposed in scheme 20 (top). The structures at the bottom show tautomeric forms possible for an enzyme-bound species. (After Bruice 1982)


Fig. 2. Spectra of intermediates in the hydroxylation reaction of phenol hydroxylase, employing resorcinol ( $2 e f t$ ) and thiopenol (wight) as substrate. Reaction conditions and calculation of spectra were similar to those described in Entsch et al. 1976a (Detmer, unpublished)

$\lambda \max \sim 400 \mathrm{~nm}$ and extinction coefficient $\sim 14,000 \mathrm{M}^{-1} \mathrm{~cm}^{-1}$, would be the ring-opened flavin. A model for this has been synthesized recently by Wessiak and Bruice (Bruice 1982), Scheme 21. The model compound has a wavelength maximum at $342 \mathrm{~nm}$ and an extinction coefficient only about half that of intermediate II of p-hydroxybenzoate hydroxylase. As pointed out by Wessiak and Bruice, their model does not necessarily rule out the ring-opened flavin intermediate, since it is possible that the enzyme or enzyme substrate complex may stabilize one of the other tautomers of the ring-opened flavin, as shown in Scheme 21 . This possibility is in accord with the recent findings of Detmer with phenol hydroxylase, where three intermediates in the oxidative half-reaction have also been observed with several substrates (Detmer and Massey, unpublished). In all cases, the spectra of intermediates I and III 
are similar to those found with p-hydroxybenzoate hydroxylase and melilolate hydroxylase (Entsch et al. 1976a; Schopfer and Massey 1980). Now, however, the spectrum of intermediate II differs markedly, depending on the substrate. This is illustrated in Fig. 2 for the substrates resorcinol and thiophenol. The finding of a high extinction intermediate II with thiophenol as substrate is similar to that with p-hydroxybenzoate hydroxylase and p-mercaptobenzoate, where hydroxylation was shown to take place at the sulfur rather than in the aromatic ring, to yield the unstable sulfenate (Entsch et al. 1976b). These findings effectively rule out the possibility that the high extinction of intermediate II is due to a complex between hydroxyflavin and a dienone tautomer of the product, since such compounds would not be formed with the sulfur-containing substrates.

Recent model studies by Bruice and colleagues (Ball and Bruice 1980; Ball and Bruice 1981) have shown that flavin hydroperoxides are surprisingly high in their reactivity towards various nucleophiles and are more comparable to organic peracids than to alkyl peroxides or $\mathrm{H}_{2} \mathrm{O}_{2}$. The finding that the $\mathrm{pK}$ of the hydroperoxide is unexpectedly low, in the region of $\mathrm{pH} 9$ (Bruice 1983), would indicate a strong -I influence of the $\mathrm{C}(4 \mathrm{a})$-substituents. A partial explanation why 1-deazaflavin substituted p-hydroxybenzoate hydroxylase (Entsch et al. 1980) is able to form a $C(4 a)$-hydroperoxide, but that this is incompetent to carry out the oxygen transfer step, might be related to its lower redox potential (Spencer et al. 1977), i.e., its smaller activation of the peroxide group. The inability of 1-deazaflavin to carry out hydroxylation, even though it is very competent in catalyzing substrate-dependent $\mathrm{NAD}(\mathrm{P}) \mathrm{H}$ oxidase activity, appears to be common with all the phenolic hydroxylases investigated (orcinol hydroxylase (Walsh 1980), p-hydroxybenzoate hydroxylase (Entsch et al. 1980), and melilotate and phenol hydroxylases (Schopfer and Detmer, unpublished). However, the fact that 2-thio FAD, which has a higher redox potential (Light and Walsh 1980), when bound to the apoenzyme of p-hydroxybenzoate hydroxylase, also forms a $C(4 a)$-hydroperoxide, which is incompetent in normal catalysis, points toward a more specific function of the $\mathrm{N}(1) \mathrm{C}(2) \mathrm{O}$ moiety in the hydroxylation reaction (Claiborne and Massey 1983). The spectral properties of 8-mercapto-FAD p-hydroxybenzoate hydroxylase suggest that the benzoquinoid form is partially stabilized in the presence of substrate (Massey et al. 1979). The spectral shifts observed were not so marked as in the case of flavoprotein oxidases, indicating the lack of a full positive charge in the $\mathrm{N}(1) \mathrm{C}(2)$ region as appears to be present in the oxidases. This is in keeping with the 3-dimensional structure of the p-hydroxybenzoate hydroxylase-substrate complex; Wierenga et al. (1982) in fact suggest that the dipole of helix 5, which starts near the flavin N(1)-position, could exert a partial positive charge towards this region of the flavin. A similar helix-induced electric dipole is present in glutathione reductase (Thieme et al. 1981), where the same type of p-quinoid 8-mercaptoflavin stabilization is found (Krauth-Siegel 1982).

Such a dipole would enhance the oxidizing power of the flavin $\mathrm{C}(4 \mathrm{a})$ hydroperoxide. At the same time, it might be related to the spectral properties of intermediate II as indicated in Scheme 22 . Here several species are depicted, in which, by different modes of interaction with the protein, different chromophoric species could be stabilized, possibly depending on different protein conformations being induced by different substrates. It must be emphasized that this is speculation, as spectral properties of the species proposed as contributing to intermediate II are difficult to correlate with those of known compounds. An interaction of position $\mathrm{N}(5)$ with the protein, such as shown in Scheme 22 , structure A, to produce the cationic species, would further enhance the electrophilicity of the flavin $\mathrm{C}(4 \mathrm{a})$ hydroperoxide, and, 


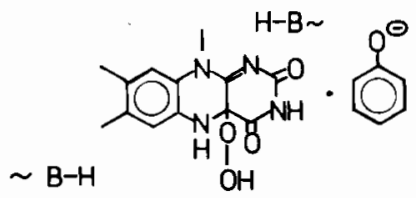

(I)<smiles>C=CC=C</smiles>

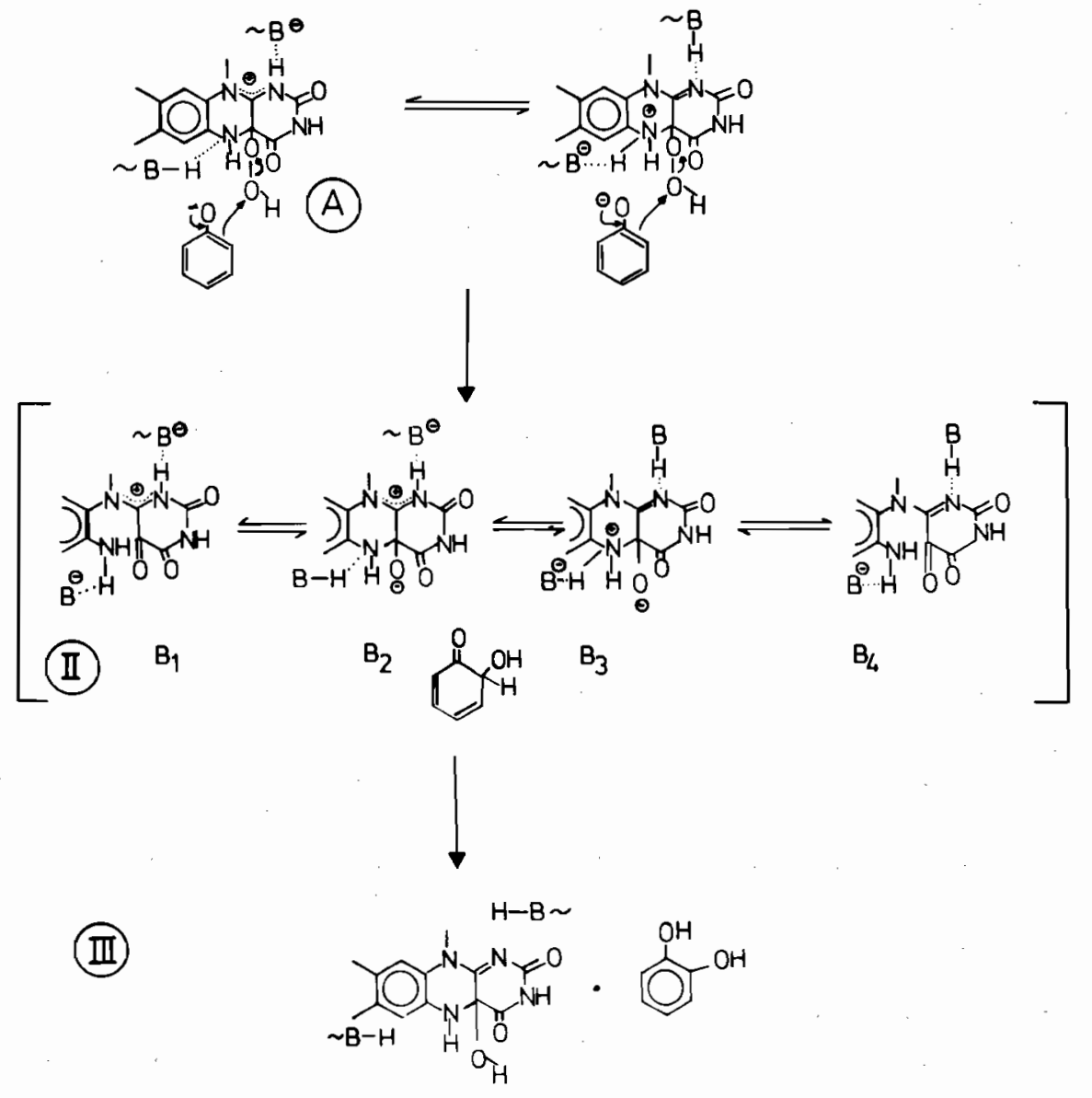

Scheme 22. Possible mechanisms of hydroxylation carried out by flavoprotein aromatic hydroxylases. The transition from intermediate I to II is shown to proceed via the protonated flavin of structures $A$. Such forms would be expected to enhance the electrophilicity of the hydroperoxide and could be induced by specific protein interactions, such as those shown. Intermediate II could be composed of any of a number of different chromophoric structures, as indicated

after oxygen transfer to substrate has occurred, lead to species, such as $\mathrm{B}_{1}$ and $\mathrm{B}_{3}$. The $\mathrm{pK}$ of protonation of $4 \mathrm{a}, 5$ dihydroflavins is known. to be in the region 2-4 (Ghisla, unpublished) making the speculation of Scheme 22 not unreasonable. Alternatively, a hydrogen bridge to $N(5)$ could constitute a driving force for the ring-opened mechanism 
already discussed (Scheme 20). Protonated 4a,5-dihydroflavins have spectra with maxima in the range $310-400 \mathrm{~nm}$ and with extinction coefficients from 3000-10000 $M^{-1} \mathrm{~cm}^{-1}$ (Ghisla et al. 1973).

Protein interactions with the flavin, such as those shown in scheme 22 , could also account for the fact that most enzymes of the aromatic hydroxylase class do not consistently stabilize either the neutral of the anionic semiquinone and that semiquinone forms, when observed, are generally dependent on the nature of the bound substrate. In the case of the remaining monooxygenases (cf. Scheme 19), the flavin hydroperoxide is remarkably stable, often with $t 1 / 2$ values in the range of minutes or even hours in the absence of the substrate to be monooxygenated. This stabilization is correlated with a corresponding stabilization of the blue neutral radical. In the case of p-hydroxybenzoate hydroxylase, the decay rate of the pseudobase intermediate III is of the order of $0.1-2 \mathrm{~s}^{-1}$ at $4^{\circ}$ (Entsch et al. 1976a). This compares with a value of $\sim 100 \mathbf{s}^{-1}$ for decay of the flavin hydroperoxide in free solution (Anderson 1982) and $<1 \mathbf{s}^{-1}$ for the $N(5)-$ substituted pseudobases studies by Ball and Bruice $(1980,1981)$. Hence it appears that no pronounced stabilization of the oxygenated flavin species is required to account for the catalytic sequence of the aromatic hydroxylases.

\section{Mechanism of $N, S$-Monooxygenation}

In the case of the microsomal flavoprotein $\mathrm{N}, \mathrm{S}$-monooxygenase, the enzyme carries out the insertion of oxygen in a wide variety of nitrogen and sulfur containing compounds, making it a valuable adjunct to the cytochrome $\mathrm{P}-450$ system in drug detoxification. Its mechanism has been investigated recently by the research groups of ziegler (Poulsen and Ziegler 1979) and Ballou (Beaty and Ballou 1981a,b). In the presence of NADP, the reduced flavoprotein forms a remarkably stable C(4a)hydroperoxide, which is discharged rapidly only when substrate is added (Beaty and Ballou 1981b). An intermediate with spectral properties similar to those of intermediate III of the phenolic hydroxylases has also been reported (Beaty and Ballou 1981b). It would appear likely that this reaction involves a simple nucleophilic attack of the $N$ or $s$ electron pair on the terminal oxygen of the flavin hydroperoxide to yield the oxygenated product and the $C(4 a)$-hydroxyflavin. The model studies of Ball and Bruice $(1980,1981)$ have shown that $N(5)-$ substituted flavin C(4a)-hydroperoxides behave in similar fashion to organic peracids in carrying out such reactions even in the absence of enzyme. Significantly, in these model studies, no aromatic ring hydroxylation by peracids or alkyl peroxides has been reported, indicating, as expected, that some extra inductive effect, such as that discussed above in scheme 22 or in the ring-opened mechanism of Entsch et al. (1976a) is required in this type of reaction.

\section{Mechanism of "Nucleophizic" Monooxygenation}

With the remaining types of flavoprotein monooxygenases, exemplified by cyclohexanone monooxygenase (Ryerson et al. 1982) and bacterial luciferase (Hastings et al. 1973), the occurrence of a flavin C(4a)hydroperoxide in the reaction pathway has also been demonstrated. Now, however, the hydroperoxide (anion) appears to function as a nucleophile, rather than as an electrophile as in the case of the phenolic hydroxylases. Ryerson et al. (1982) propose the following mechanism for cyclohexanone monoxygenase based on a steady state and rapid reaction kinetics study (Scheme 23). 
$\mathrm{E} \cdot \mathrm{FH}_{2} \cdot \mathrm{S}+\mathrm{O}_{2}$<smiles>[R]N1c2cc(C)c(C)cc2C(=O)Nc2[nH]c(=O)[nH]c(=O)c21</smiles><smiles>C=CC=C</smiles>

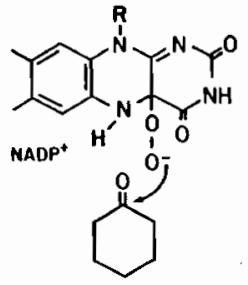<smiles>C1=CC=C1</smiles><smiles>CC(C)NNC(C)(C)S</smiles><smiles>[R]n1c2nc(=O)[nH]c(=O)c-2nc2cc(C)c(C)cc21</smiles>

E·FAD<smiles>CCC(C)(C)O</smiles>

E.FAD $\cdot P$

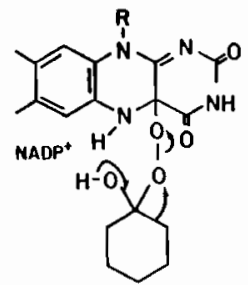

Scheme 23. Proposed reaction mechanism of $\mathrm{cy}^{-}$ clohexanone monooxygenase, involving the flavin hydroperoxide as a nucleophile. (From Ryerson et al. 1982)

In this mechanism, the terminal oxygen of the hydroperoxide makes a nucleophilic attack on the electrophilic carbonyl carbon of the substrate. The tetrahedral adduct formed then decomposes to $\mathrm{C}(4 \mathrm{a})-\mathrm{hy}-$ droxyflavin with a Baeyer-Villiger $\mathrm{C} \rightarrow \mathrm{O}$ bond migration to incorporate the terminal oxygen atom into the substrate ring. With this enzyme, it is interesting to note that enzyme with 1-deazaflavin incorporated instead of the native FAD is fully competent in carrying out the complete catalytic reaction, distinguishing it in yet another way from the phenolic hydroxylases.

Similar mechanisms have been proposed for the bacterial luciferase reaction, but details of this intriguing biological phenomenon are still uncertain. It has been well established that the flavin $\mathrm{C}(4 \mathrm{a})-$ hydroperoxide is the primary product of reaction of the reduced luciferase flavin with $\mathrm{O}_{2}$. This hydroperoxide is remarkable in its stability in the absence of long chain aldehyde substrate (Hastings et al. 1973) and can be further stabilized by addition of long chain alcohols and/or high electrolyte concentration (Tu 1979; Becvar et al. 1978). The stabilization of the hydroperoxide is essentially kinetic in its nature and was found to parallel a similar stabilization of the blue flavin semiquinone (Kurfüst et al. 1982b); the mechanisms of the two processes were proposed to involve a strong $\mathrm{H}$-bridge from the protein to the flavin position $\mathrm{N}(5)-\mathrm{H}$ as shown on scheme 24 .

For the mechanism of substrate oxidation and concomitant generation of an excited state, a series of imaginative proposals have been put



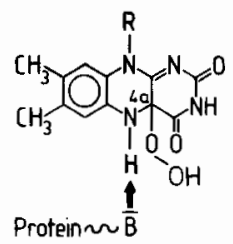

Scheme 24. Proposed stabilization of luciferase flavin $\mathrm{C}(4 \mathrm{a})$-hydroperoxide and neutral flavin radical by hydrogen bonding of the flavin $\mathrm{N}(5) \mathrm{H}$ with the protein 
forward in the past (Kosower 1980; Mager and Addink 1979; Wessiak et al. 1980). They have mechanistic features, such as migration of the peroxide residue, ring openings, and closure, and the generation of an N(1) protonated flavin as the emitter. Many of these proposals have been addressed by a specific experiment involving the use of 1-deazaFMN, a flavin analogue which cannot undergo the type of reactions proposed which involve position 1 or protonation at this locus. This analoge was found to be competent in light emission and the spectrum of the emitted light clearly excludes a protonated species as the emitter (Kurfürst et al. 1982a).

Recent work has provided evidence that the oxidation of aldehyde indeed follows the pattern already demonstrated for the monooxygenases discussed above. Kinetic analysis of the steps following addition of aldehyde to the peroxide, shows that a species is present after most of the light has been emitted, which shares the spectral properties common to $4 \mathrm{a}, 5$-dihydroflavins (Kurfürst and Ghisla, unpublished). Its

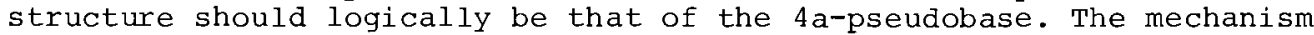
of bacterial luciferase can be envisaged as shown in Scheme 25 . It involves a nucleophilic attack of the peroxide anion at the aldehyde function followed by a Baeyer-villiger type reaction leading to the corresponding carboxylic acid and the flavin $\mathrm{C}(4 \mathrm{a})$ hydroxy derivative (pseudobase). The question as to what is the primary excited chromophore is still unsettled. The flavin pseudobase clearly can exert this function, as shown also by experiments involving the use of specifically modified flavin chromophores (Kurfürst et al. 1982a; Tu 1982). In these experiments, it was demonstrated that the emission profile of bioluminescene was closely matched by the fluorescence emission spectrum of the corresponding flavin C(4a)-hydroperoxide. In some cases, (Leisman and Nealson 1982; Koka and Lee 1979), a second protein chromophore can accept the (primary) excitation and serve as the emitter. Whether the flavin pseudobase is an obligatory intermediate in such energy transfer will have to await further experimental analysis.

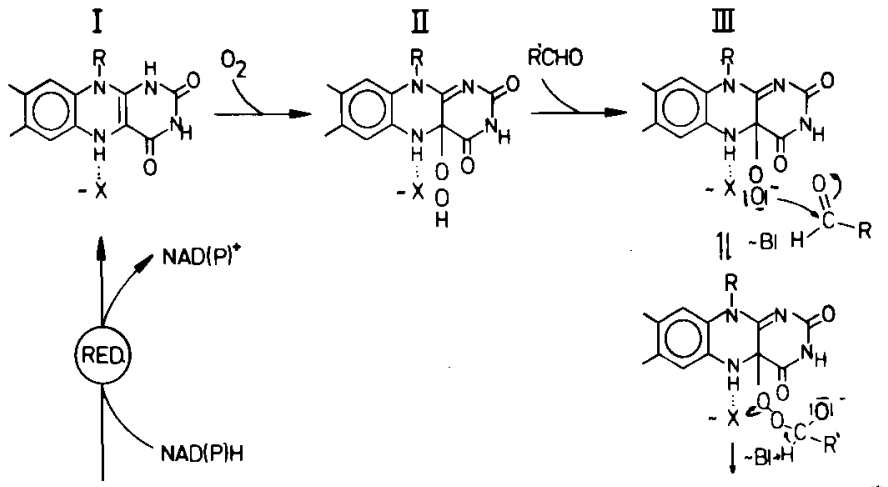

Scheme 25. Proposed reaction mechanism of bacterial luciferase. Enzyme-bound $\mathrm{FMNH}_{2}$ (I) reacts with $\mathrm{O}_{2}$ to yield the stable hydroperoxide (II). On addition of long chain aldehydes a Baeyer-Villiger type reaction is envisaged (III and IV), which leads to the excited emitter $V$. Upon emission of light, the pseudobase VI is formed, which generates oxidized flavin VII by the elimination of $\mathrm{H}_{2} \mathrm{O}$. Formation of reduced flavin I from VII requires an external NAD (P) H-FMN reductase. (From Kurfürst and Ghisla, unpublished) 
Acknowledgements. The authors wish to acknowledge support from the U.S. Public Health Service, Grant GM 11106 and from the DFG, Grant Gh 2/4-4. We wish to thank our colleagues, Drs. A Claiborne, K Detmer, M Kurfürst, LM Schopfer, A Wenz, and A wessiak for permission to quote unpublished work and for many valuable discussions.

$\underline{\underline{\text { Discussion }}}$

Biellmann: Glucose oxidase is inactivated after $10^{7}$ turnovers, methionine being oxidized to sulfoxide. Since intermediates in flavoprotein catalyzed reactions should be very reactive, are flavoproteins inactivated after a certain number of turnovers?

Massey: Sometimes inactivation does occur, but this is generally the result of reaction with active products rather than intermediates. For example, flavoenzymes, such as glucose oxidase, produce $\mathrm{H}_{2} \mathrm{O}_{2}$ as a result of turnover with $\mathrm{O}_{2}$ as acceptor and $\mathrm{H}_{2} \mathrm{O}_{2}$ can often oxidize exposed sensitive amino acid residues. Perhaps the inactivation you refer to is of this sort.

Mason: Your elucidation of the biological oxygen reactions catalyzed by flavoproteins is very beautiful. It is very interesting that the same range of reactions is catalyzed by the other $\mathrm{O}_{2}$-activating prosthetic groups, $\mathrm{Cu}, \mathrm{Fe}$, and heme, except that two classes of enzyme reactions are missing: reversible $\mathrm{O}_{2}$ transport and dioxygenation. Are these possible for flavoproteins too?

Massey: Dioxygenation is certainly possible; a flavoprotein dioxygenase has been studied by snell and co-workers over a number of years. Their enzyme catalyzes ring-opening of the pyridine ring in the bacterial metabolism of pyridoxal. The second property, of reversible $\mathrm{O}_{2}$ transport, seems to be one which flavoproteins are not designed for.

Ruf: The leukocyte pyridine nucleotide oxidase generates $\mathrm{O}_{2}^{-}$during phagocytosis at high rates. Schirmer showed this enzyme as a protein with one flavin. Can you conceive a mechanism for rapid one-electron reduction of $\mathrm{O}_{2}$ by such a protein without the need for an additional one-electron acceptor, such as a cytochrome?

Massey: In principle this should be possible with a single flavin-containing protein. Some flavoproteins, such as flavodoxin, react rapidly in their reduced form with $\mathrm{O}_{2}$ to produce the flavin semiquinone and $\mathrm{O}_{2}^{-}$. In this case, the reaction of the semiquinoid protein with $\mathrm{O}_{2}$ is slow, so that the overall reaction $\mathrm{Fl} \mathrm{red}_{2} \mathrm{H}_{2}+2 \mathrm{O}_{2} \rightarrow \mathrm{Fl}_{\mathrm{Ox}}+2 \mathrm{O}_{2}$ $+{ }^{+} \mathrm{H}^{+}$is slow. But in principle there seems to be no real reason why the reaction of flavoprotein semiquinone with $\mathrm{O}_{2}$ need be slow. We have shown that the neutral radical form of glucose oxidase reacts rapidly with $\mathrm{O}_{2}$ to generate $\mathrm{O}_{2}^{-}$. So, while nature may choose often to use a second redox acceptor as an electron sink, I would not be surprised that some day a simple flavoprotein will be found to do this conversion efficiently in a catalytic fashion.

Schimer: Could you please comment on the turnover numbers of the different types of flavoenzymes?

Massey: I cannot think of any real generalization about the various classes. Some oxidases, like glucose oxidase, have very high turnover numbers, of the order of $50000 \mathrm{~min}^{-1}$ at $25^{\circ}$, while others, such as D-amino acid oxidase have turnover numbers around $1000 \mathrm{~min}^{-1}$. The monooxygenases have medium catalytic rates, of the order of $1000-10000$ $\mathrm{min}^{-1}$. Some transhydrogenases, such as lipoyl dehydrogenase, have very 
high turnover numbers, again in the region of $50000 \mathrm{~min}^{-1}$. But in fairness to the catalytic efficiency of the flavin molecule, it should be mentioned that in some cases, such as that of $\mathrm{D}$-amino acid oxidase, the rate-limiting step is the dissociation of product from the enzyme!

Ullrich: With regard to the structure of intermediate II, do you think that it could correspond to either the peroxide anion or an endoperoxide-type intermediate with the substrate on one side?

Massey: It is unlikely that intermediate II could be the flavin hydroperoxide anion, since our rapid chemical quench data indicate that oxygen transfer to substrate occurs coincident with the formation of intermediate II. With an endoperoxide the rapid quench data could be explained by acid breakdown of the endoperoxide so that dihydroxyproduct would be found. However, I doubt that this would have a spectrum significantly different from that of the hydroperoxide (intermediate I).

\section{$\underline{\underline{\text { References }}}$}

Anderson RF (1982) In: Massey V, Williams CH (eds) Flavins and flavoproteins.

Elsevier North Holland, Amsterdam, pp 278-283

Arscott LD, Thorpe C, Williams CH Ir (1981) Biochemistry 20:1513-1519

Ball S, Bruice TC (1980) J Amer Chem Soc 102:6498-6503

Ball S, Bruice TC (1981) J Amer Chem Soc 103:5494-5503

Ballou DP (1982) In: Massey $\mathrm{V}$, Williams $\mathrm{CH}$ (eds) Flavins and flavoproteins.

Elsevier North Holland, Amsterdam, pp 301-310

Beaty NB, Ballou DP (1981a) J Biol Chem 256:4611-4618

Beaty NB, Ballou DP (1981b) J Biol Chem 256:4619-4625

Becvar JE, Tu S, Hastings JW (1978) Biochemistry 17:1807-1812

Biellmann JF, Hirth CG (1970) FEBS Letters 9:335-336

Bruice TC (1982) In: Massey V, Williams CH (eds) Flavins and flavoproteins. Elsevier North Holland, Amsterdam, pp 265-277

Bruice TC (1983) J Chem Soc Chem Commun 1983:14-15

Brüstlein M, Bruice TC (1972) J Amer Chem Soc 94:6548

Claiborne A, Massey V, Fitzpatrick PF, Schopfer IM (1982) J Biol Chem 257:174-182

Claiborne A, Massey V (1983) J Biol Chem 258:4919-4925

Cromartie TH, Walsh CT (1976) J Biol Chem 251:329-333

Dudley KH, Ehrenberg A, Hemmerich P, Müller F (1964) Helv Chim Acta 47:1354-1383

Edmondson DE, Singer TP (1976) FEBS Letters 64:255-265

Ehrenberg A, Müller F, Hemmerich P (1967) Eur J Biochem 2:286-293

Entsch B, Massey V, Ballou DP (1974) Biochem Biophys Res Comm 57:1018-1025

Entsch B, Ballou DP, Massey V (1976a) J Biol Chem 251:2550-2563

Entsch B, Ballou DP, Husain M, Massey V (1976b) J Biol Chem 251:5367-7379

Entsch B, Husain M, Ballou DP, Massey V, Walsh C (1980) J Biol Chem 255:1420-1429

Fendrich G, Abeles RH (1982) Biochemistry 21:6685-6695

Ferti C, Curti B, Simonetta MP, Ronchi S, Galliano M, Minchiotti L (1981) Eur J Biochem 119:553-557

Fitzpatrick PF, Massey V (1983) J Biol Chem 258:9700-9705

Frerman FE, Miziorko HM, Beckmann JD (1980) J Biol Chem 255:11192-11198

Fox B, Walsh CT (1982) J Biol Chem 257:2498-2503

Geissler J, Hemmerich P (1981) FEBS Letters 126:152-156

Ghisla S, Massey V (1980) J Biol Chem 255:5688-5696

Ghisla S, Hartmann U, Hemmerich P, Müller F (1973) Liebigs Ann Chem 1973:1388-1415

Ghisla S, Entsch B, Massey V, Husain M (1977) Eur J Biochem 76:139-148

Ghisla S, Hastings JW, Favaudon V, Lhoste JM (1978) Proc Nat Acad Sci USA 75 : $5860-5863$

Gibson QH, Hastings JW (1962) Biochem J 68:368-377

Gibson QH, Swoboda BEP, Massey V (1964) J Biol Chem 239:3927-3934 
Hastings JW, Balny C, Le Peuch C, Douzou P (1973) Proc Natl Acad Sci USA 70:3468-3472 Hemmerich P, Massey V, Fenner H (1977) FEBS Letters 84:5-21

Hemmerich P, Massey V, Michel H, Schug C (1982) Structure and bonding 48:93-123 Jorns MS (1980) In: Yagi K, Yamano T (eds) Flavins and flavoproteins. Univ Park Press, Baltimore, pp 161-172

Kamin $\mathrm{H}$, Lambeth JD (1982) In: Massey V, Williams CH (eds) Flavins and flavoproteins. Elsevier North Holland, Amsterdam, pp 655-666

Kawaguchi A, Tsubotani S, Seyama Y, Yamakawa T, Osumi T, Hashimoto T, Kikuchi T, Ando M, Okuda S (1980) J Biochem 88:1481-1484

Kemal C, Bruice TC (1976) Proc Natl Acad Sci USA 73:995-999

Kemal C, Chan TW, Bruice TC (1977) J Amer Chem Soc 99:7272-7286

Koka P, Lee J (1979) Proc Natl Acad Sci USA 76:3068-3072

Kosower EM (1980) Biochem Biophys Res Commun 92:356-364

Kuhn R, Wagner-Jauregg $T$ (1933) Ber 66:1577-1582

Krauth-Siegel RL (1982) Ph D Thesis, Heidelberg p 44

Kurfürst M, Ghisla S, Hastings JW (1982a) In: Massey V, Williams CH (eds) Flavins and flavoproteins. Elsevier North Holland, Amsterdam, pp 353-358

Kurfürst M, Ghisla S, Presswood R, Hastings JW (1982b) Eur J Biochem 123:355-361

Land EJ, Swallow AJ (1969) Biochemistry 8:2117-2125

La Roche HJ, Kellner M, Günther H, Simon H (1971) Hoppe-seyler's Z Phys Chem 352: 399-402

Leisman G, Nealson KH (9182) In: Massey V, Williams CH (eds) Flavins and flavoproteins. Elsevier North Holland, Amsterdam, pp 383-386

Light DR, walsh C (1980) J Biol Chem 255:4264-4277

Lockridge O, Massey V, Sullivan PA (1972) J Biol Chem 247:8097-8106

Loechler EL, Hollocher TC (1975) J Amer Chem Soc 97:3225-3237

Ludwig M, Burnett RM, Darling GD, Jordan SR, Kendall DS, Smith WW (1976) In: Singer TP (ed) Flavins and flavoproteins. Elsevier North Holland, Amsterdam, pp 393-404

Ludwig M, Pattridge KA, Smith WW, Jensen LH, Watenpaugh KD (1982) In: Massey V, Williams $\mathrm{CH}$ (eds) Flavins and flavoproteins. Elsevier North Holland, Amsterdam, pp 19-27

Mager HJ, Addink R (1979) Tetrahedron Letters 37:3545-3548

Massey V, Veeger C (1960) Biochim Biophys Acta 40:184-185

Massey V, Gibson QH (1963) Federation Proc 23:18-29

Massey V, Williams CH Jr (1965) J Biol Chem 240:4470-4480

Massey V, Ghisla S (1974) Ann NY Acad Sci 227:446-465

Massey V, Hemmerich P (1975) In: Boyer PD (ed) The enzymes. Academic, New York, Vol 12, pp 191-252

Massey V, Hemnerich P (1980) Biochem Soc Transactions 8:246-257

Massey V, Müller F, Feldberg R, Schuman M, Sullivan PA, Howell LG, Mayhew SG, Matthews RG, Foust GP (1969) J Biol Chem 244:3999-4006

Massey V, Palmer G, Ballou DP (1973) In: King TE, Mason HS, Morrison M (eds)

Oxidases and related redox systems. University Park Press, Baltimore, pp 25-49

Massey V, Ghisla S, Moore EG (1979) J Biol Chem 254:9640-9650

Mincey T, Tayrien G, Mildvan AS, Abeles RH (1980) Proc Natl Acad Sci USA 77: 7099-7101

Müller F (1972) zeitschrift Naturforschung 27b:1023-1026

Müller F, Massey V (1969) J Biol Chem 244:4007-4016

Müller F, Massey V, Heizmann C, Hemmerich P, Lhoste JM, Gould DC (1969) Eur J Biochem 9:392-401

Nanni EJ, Sayer DT, Ball SS, Bruice TC (1981) J Amer Chem Soc 103:2797-2802

Pai EF, Schulz GE (1982) In: Massey V, Williams CH (eds) Flavins and flavoproteins. Elsevier North Holland, Amsterdam, pp 3-10

Platenkamp RJ, Palmer MH, Visser AJ (1980) J Mol Structure 67:45-64

Porter DJT, Voet JB, Bright HJ (1973) J Biol Chem 248:4400-4416

Poulsen LL, Ziegler DM (1979) J Biol Chem 254:6449-6455

Reinsch J, Katz A, Wean J, Aprahamian G, McFarland J (1980) J Biol Chem 255:9093-9097 Ronchi S, Minchiotti L, Galliano M, Curti B, Swenson RP, Williams CH Jr, Massey V (1982) J Biol Chem 257:8824-8834

Ryerson CC, Ballou DP, walsh C (1982) Biochemistry $21: 2644-2655$

Searls RL (1960) Federation Proc 19:36

Schopfer LM, Massey V (1980) J Biol Chem 255:5355-5363 
Schulz GE, Schirmer RH, Pai EF (1982) J Mol Biol 160:287-308

Silverman RB, Hoffman SJ, Catus WB (1982) In: Massey V, Williams CH (eds) Flavins and flavoproteins. Elsevier North Holland, Amsterdam, pp 213-216

Swenson RP, Williams CH Jr, Massey V (1982) J Biol Chem $257: 1937-1944$

Swenson RP, Williams CH Jr, Massey V (1983) J Biol Chen 258:497-502

Spector T, Massey V (1972) J Biol Chem 247:5632-5636

Spencer R, Fisher J, Walsh C (1977) Biochemistry 16:3586-3594

Strickland S, Massey V (1973) J Biol Chem 248:2953-2962

Thieme R, Pai EF, Schirmer RH, Schulz GE (1981) J Mol Biol 152:763-782

Thorpe C, Williams CH Jr (1981) Biochemistry 20:1507-1513

Tu S (1979) Biochemistry 18:5940-5945

Tu S (1982) J Biol Chem 257:3719-3725

Walsh C (1979) Enzymatic reaction mechanisms. WH Freeman, San Francisco, Chapters 11 and 12

Walsh C (1980) Acc Chem Research 13:148-155

Walsh C, Schonbrunn A, Abeles RH (1971) J Biol Chem 246:6855-6866

Walsh C, Krodel E, Massey V, Abeles RH (1973a) J Biol Chem 248:1946-1955

Walsh C, Lockridge O, Massey V, Abeles RH (1973b) J Biol Chem 248:7049-7054

Warburg O, Christian W (1933) Biochem Z 266:377-414

Wessiak A, Trout GE, Hemmerich P (1980) Tetrahedron Letters $21: 739-742$

Wenz A, Ghisla S, Thorpe C (1982) In: Massey V, Williams CH (eds) Flavins and flavoproteins. Elsevier North Holland, Amsterdam, pp 605-608

Wierenga RK, de Jong RJ, Kalk KH, Hol WGJ, Drenth J (1979) J Mol Biol 131:55-73

Wierenga RK, Kalk KH, van der Laan JM, Drenth J, Hofsteenge J, Weisser WJ, Jeker

PA, Beintema JJ, Müller F, van Berkel WJH (1982) In: Massey V, Williams CH (eds)

Flavins and flavoproteins. Elsevier North Holland, Ansterdam, pp 11-18

Williams $\mathrm{CH}$ Jr (1.976) In: Boyer $\mathrm{PH}$ (ed) The enzymes, 3rd ed Vol 13. Academic, New York, pp 89-172

Zanetti G, Williams CH Jr (1967) J Biol Chem 240:5232-5236 